(c) Elsevier/INRA

Original article

\title{
Resistance to experimental infections with Haemonchus contortus in Romanov sheep
}

\author{
G Luffau ${ }^{1}, J$ Vu Tien Khang ${ }^{2 *}$, J Bouix ${ }^{2}$, TC Nguyen ${ }^{3}$, \\ P Cullen ${ }^{4}$, G Ricordeau ${ }^{2}$ \\ with the technical assistance of C Carrat, F Eychenne \\ Institut National de la Recherche Agronomique; \\ ${ }^{1}$ Station de Virologie et d'Immunologie, Centre de Recherches de Jouy-en-Josas, \\ 78350 Jouy-en-Josas; \\ ${ }^{2}$ Station d'Amélioration Génétique des Animaux, Centre de Recherches de Toulouse, \\ BP 27, 31326 Castanet-Tolosan Cedex; \\ ${ }^{3}$ Laboratoire des Groupes Sanguins, Centre de Recherches de Jouy-en-Josas, \\ 78350 Jouy-en-Josas; \\ ${ }^{4}$ Laboratoire de Génétique Biochimique, Centre de Recherches de Jouy-en-Josas, \\ 78350 Jouy-en-Josas, France
}

(Received 22 August 1989; accepted 28 February 1990)

Summary - Responses to immunization with aggregated human serum albumin (HSA) and to repeated experimental infections with $H$ contortus were studied in 51 female lambs of the Romanov breed, born from 8 sires and 36 dams. The 8 sires were of haemoglobin genotype $H b A B$; the 51 lambs were distributed into 3 groups of 17 each, corresponding to the 3 genotypes $H b A A, H b A B$ and $H b B B$. In addition, the experimental lambs were typed for antigens of the major histocompatibility system $(O L A)$. The parasitological findings were the following: a repeatability of faecal egg counts between successive infections, a negative correlation between peak faecal egg counts and self-cure intensity, a positive correlation between faecal egg counts and degree of anaemia, an acquisition of immunity to the parasite by previous contact with the parasite and a reduction of this immunity by anthelmintic treatment. According to the genetic investigations, there were significant sire effects on variables reflecting the resistance. The faecal egg counts did not seem to be related to the haemoglobin system, but might be affected by 1 or several genes located in the OLA complex or close to the latter. The humoral response to HSA showed a negative correlation to parasite resistance.

sheep / Haemonchus contortus / humoral response / haemoglobin / OLA system

Résumé - Résistance à des infestations expérimentales par Haemonchus contortus en race ovine Romanov. Les réponses à une immunisation avec de la sérum albumine humaine agrégée (SAH) et à des infestations expérimentales répétées avec $\mathrm{H}$ contortus ont été étudiées chez 51 agnelles de race Romanov, issues de 8 pères et de 36 mères. Les 8 pères étaient hétérozygotes $\mathrm{AB}$ pour le système hémoglobine (Hb) et les 51 agnelles

* Correspondence and reprints 
étaient réparties en trois groupes de 17 correspondant aux trois génotypes $\mathrm{Hb} \mathrm{AA}, \mathrm{Hb} \mathrm{AB}$ et $\mathrm{Hb} \mathrm{BB}$. Par ailleurs, les agnelles expérimentales ont été typées pour le système majeur d'histocompatibilité (OLA). Sur le plan parasitologique, les résultats obtenus mettent en évidence: une répétabilité du taux d'excrétion des oufs entre infestations successives, une corrélation négative entre niveaux des pics d'excrétion et intensité de l'autostérilisation ("self-cure"), une corrélation positive entre taux d'excrétion et degré d'anémie, une acquisition de l'immunité parasitaire par contact préalable avec le parasite et une réduction de cette immunité par vermifugation. Sur le plan génétique, on observe des effets père significatifs sur des variables reflétant la résistance. Le système hémoglobine ne semble pas lié au taux d'excrétion mais pourrait être lié au degré d'anémie consécutif à l'infestation. La résistance à $\mathrm{H}$ contortus pourrait être influencée par un ou plusieurs gènes situés dans le complexe OLA ou à sa proximité. La réponse humorale à la SAH présente une corrélation négative avec la résistance au parasite.

ovin / Haemonchus contortus / réponse humorale / hémoglobine / système OLA

\section{INTRODUCTION}

Since the publications of Warwick et al (1949), Whitlock $(1955,1958)$ and Whitlock and Madsen (1958), the existence of a genetic variability in the resistance to Haemonchus contortus has been shown in several studies: the heritability estimates range around 0.25-0.30 (Le Jambre, 1978; Albers et al, 1984, 1987; Piper, 1987). As there are almost no genetic correlations between the resistance and various production traits (Alberts et al, 1984, 1987; Piper, 1987), selection on resistance to $H$ contortus would be possible and economically justified in conditions where this type of parasitism leads to large productivity losses (Holmes, 1986). However, it does not seem to be possible to use the response to an experimental infection as a largescale selection criterion because of the difficulties of such an experimentation. It would therefore be interesting to identify resistance predictors, either immunological traits or genetic markers (Courtney, 1986; Alberts and Gray, 1987; Cabaret and Gruner, 1988).

Several studies suggest that haemoglobin $A$ allele provides a higher resistance to $H$ contortus than the haemoglobin $B$ allele (Evans et al, 1963; Jilek and Bradley, 1969; Radhakrishnan et al, 1972; Allonby and Jrquhart, 1976; Altaif and Dargie, 1976, 1978a, b; Preston and Allonby, 1979; Dally et al, 1980; Luffau et al, 1981a, b; Courtney et al, 1985). According to Cuperlovic et al (1978), this enhanced resistance might be related to a higher humoral immune response.

From a genetic point of view, the main objective of the present experiments was to confirm or invalidate this hypothesis. Because the typing of animals in the major histocompatibility system $(O L A)$ was performed retrospectively, a search for relationships between resistance to $H$ contortus and the $O L A$ marker was also included in this study.

From a parasitological point of view, the experimental goals were to supply additional information on the following phenomena: repeatability of faecal egg counts between successive infections, relationship between egg counts and self-cure, relationship between egg counts and degree of anaemia, acquisition of immunity to the parasite by previous contact with the parasite and effect of anthelmintic treatment on this acquired immunity.

The experiment was designed so as to give responses to questions in the fields of genetics and parasitology. 


\section{MATERIALS AND METHODS}

\section{Animals}

Several studies have shown that females develop stronger immunity against $H$ contortus than males (Colglazier et al, 1968; Yazwinski et al, 1980; Luffau et al, 1981a; Courtney et al, 1985; Watson, 1986): hence only females were used in the present study, ie 51 female lambs of the Romanov breed born from 8 sires and 36 dams. The breeding animals were chosen according to their haemoglobin genotype. All sires were $H b A B$ heterozygotes. The dams belonged to genotypes $H b A A, H b A B$ or $H b B B$. The 51 lambs fell into 3 groups of 17, each representing 1 of the 3 haemoglobin genotypes. The number of animals in the 3 haemoglobin genotypes was balanced within each sire progeny so as to reduce risks of confusion between a possible haemoglobin genotype effect and a possible sire effect.

Fifty lambs and 24 of their 35 dams were typed for antigens of the $O L A$ system. The sires were not typed but their genotypes could be inferred and transmission of markers determined in many cases.

The experimental female lambs were chosen so as to form a group as homogeneous as possible for age, weight, maintenance conditions and health in order to reduce uncontrolled factors of variation. The animals were maintained on a grass free diet from birth to avoid environmental exposure to $H$ contortus.

\section{Typing methods for haemoglobin and OLA systems}

Haemoglobin types were determined by electrophoresis (Nguyen and Bunch, 1980). Class I antigens of the major histocompatibility system were tested by the microcytotoxicity method on blood lymphocytes; the test was carried out over a period of $2 \mathrm{~h} 30 \mathrm{~min}$ (Cullen et al, 1985). Lymphocytes of each animal were tested with 120 antisera against 22 provisional specificities, "OLA-P". Nine haplotypes, each carrying 1 or 2 specificities, were identified in the tested animals.

\section{Immunization experiments with aggregated human serum albumin}

The 51 experimental lambs were immunized at the age of about 6 months with heat aggregated human serum albumin (HSA: $200 \mathrm{mg} /$ animal) by intravenous injection. Their serum was collected before and $14 \mathrm{~d}$ after the administration of the antigen, titred by passive haemagglutination using red blood cells tanned and sensitized with HSA (Weir, 1978). The technique used to determine the serum agglutination titre has been described previously (Nguyen, 1984).

\section{Experimental infections with $\mathrm{H}$ contortus}

According to various studies, sheep develop immunity against $H$ contortus from the age of about 7 months (Jarrett et al, 1961; Manton et al, 1962; Urquhart et al, 1966a, b; Knight and Rodgers, 1974; Wilson and Samson, 1974; Benitez-Usher et al, 1977; Duncan et al, 1978; Riffkin and Dobson, 1979; Smith and Angus, 1980). Our experiments therefore began when the lambs were about 8 months old. During the experimental infections, lambs were kept in well controlled conditions: open 
sheepfold fitted with a slatted floor, diets based on compound feed concentrates, hay and straw ad libitum. Five infection experiments were conducted successively using 3-week old larvae. Animals were infected with larvae obtained by faecal cultures according to the method of FJS Robert and PJ O'Sullivan and collected with Baerman's apparatus (Luffau et al, 1981a, b). The required number of larvae were counted microscopically and suspended in $20 \mathrm{ml}$ of ordinary water. This suspension was administered orally. The strain maintained at the Station of Virology and Immunology was supplied initially by Professors GM Urquhart and EW Allonby (Glasgow).

\section{Experiment 1}

In experiment 1 , lambs were divided into 3 groups:

- 18 animals were given 3 infections successively: a primary infection on D0 with 5000 larvae, a secondary one on D32 with 10000 larvae and a 3rd one on D64 with 20000 larvae (group 1);

- 18 animals were given 2 infections successively: a primary infection on D32 with 10000 larvae and a secondary one on D64 with 20000 larvae (group 2);

- 15 animals were given an infection of 20000 larvae on D64 (group 3).

The 3 groups were formed so as to obtain a balanced distribution of the various paternal origins and haemoglobin genotypes.

The kinetics of faecal egg counts was established for each animal. Eggs laid by $H$ contortus females and eliminated with the faeces were counted using faecal samples of $3 \mathrm{~g}$ using the Mc Master method. Measurements were made on the following 40 dates: D17, D21, D24, D28, D31, D35, D37, D39, D42, D44, D46, D49, D51, D53, D56, D58, D60, D63, D65, D67, D70, D72, D74, D77, D79, D81, D84, D86, D88, D91, D95, D98, D107, D114, D119, D126, D133, D140, D147 and D156. Each measure (number of eggs per gram) was the mean egg count of 3 different samples. These egg counts were good indicators of the worm burdens of the animals (Roberts and Swan, 1981).

The following 3 haematological parameters were recorded in all animals: number of red blood cells, packed cell volume and haemoglobin content. These measurements were made on the following dates: D9, D16, D23, D30, D39, D45, D53, D58, D67, D74, D88, D95, D102, D109, D116, D123, D130, D137, D144, D151 and D158.

The number of red blood cells (per $\mu \mathrm{l}$ of blood) was determined by measuring the variation in the potential difference (Celloscope 401 - Ljungberg - Stockholm, Sweden) induced by the passage of red blood cells (blood dilution 1/800) in an electric field. The apparatus was periodically checked according to the microscopical method of Malassez.

For measuring haematocrit (packed cell volume), blood was centrifuged in heparinized capillary tubes (inner diameter: $0.55 \mathrm{~mm}$; length: $75 \mathrm{~mm}$ ) using Janetzki's TH-12 centrifuge at $1500 \mathrm{r} / \mathrm{min}$ for $5 \mathrm{~min}$.

For measuring the haemoglobin content $(\mathrm{g} / 100 \mathrm{ml}$ blood), haemoglobin of the red blood cells lysed by saponin was fixed and transformed into cyanmethaemoglobin. The haemoglobin content was measured by spectrophotometry (absorption at $630 \mathrm{~nm})$. 


\section{Experiment 2}

The surviving 49 animals were divided into 2 groups, irrespective of the group they were part of in experiment 1 :

- the 26 animals of group 1 were not drenched prior to experiment 2; hence they were carriers of a residual $H$ contortus population;

- before starting experiment 2 the 23 animals of group 2 were drenched with a highly effective anthelmintic, Thibenzole MSD powder (thiazolyl benzimidazolethiabendazole ND, Paris, France).

In these 2 groups, each animal was given 10000 larvae on D0 of experiment 2 (263 days after $\mathrm{D} 0$ of experiment 1 ). Faecal egg counts were made on the following 20 dates: D1, D0, D17, D20, D24, D27, D31, D34, D38, D41, D45, D48, D56, D59, D80, D83, D88, D91, D95 and D98.

\section{Experiment 3}

Experiment 3 was a replication of experiment 2. The infection on D0 took place 366 days after $\mathrm{D} 0$ of experiment 1 . The faecal egg counts were made on the following 18 dates: D5, D8, D9, D12, D15, D19, D22, D26, D29, D33, D36, D40, D43, D47, D50, D54, D57 and D64.

\section{Experiment 4}

In experiment 4, each animal was drenched and given 10000 larvae on D0 (485 days after D0 of experiment 1). The faecal egg counts were made at the following 19 dates: D5, D0, D3, D6, D10, D15, D19, D22, D26, D29, D33, D36, D40, D44, D47, D50, D55, D65 and D72.

\section{Experiment 5}

Experiment 5 was a replication of experiments 2 and 3 . The animals of each group (drenched and not drenched) were given 10000 larvae on D0 (560 days after D0 of experiment 1). The faecal egg counts were made on the following 41 dates: D0, D17, D21, D24, D28, D31, D35, D38, D42, D45, D49, D52, D56, D59, D63, D70, D73, D77, D80, D84, D87, D91, D94, D98, D101, D108, D115, D119, D123, D126, D129, D140, D143, D147, D150, D154, D157, D161, D164, D168 and D172.

\section{Statistical analysis}

\section{Choice of variables and factors}

\section{Variables}

The immunological, parasitological and haematological variables used are given in table I. The parasitological variables were defined from decimal logarithms of mean egg counts over certain periods (in order to normalize distributions and obtain more homogeneous variances). The choice of periods was based on the kinetics of faecal eggs counts in the successive infection experiments. 
Table I. List of immunological, parasitological and haematological variables in experiments $1,2,3,4$ and 5. ${ }^{*}$ HSA: aggregated human serum albumin. ${ }^{* *}$ mean $\log$ epg from $D n$ to $D n^{\prime}$ : variable equal to 0 if the mean $\log$ epg from $D n$ to $D n^{\prime}$ is equal to 0 ; variable equal to the decimal logarithm of the mean epg from $D n$ to $D n^{\prime}$ if not. ${ }^{* * *}$ The reference periods used to calculate the means in groups 1,2 and 3 were the same as for the $R B C P R I M$ variable.

\begin{tabular}{ll}
$\begin{array}{l}\text { Name of } \\
\text { variable }\end{array}$ & Definition of variable \\
\hline$A N T I H S A$ & $\begin{array}{l}\text { Inverse of the anti-HSA* antibody titre (2 for a titre of } 1 / 2,4 \text { for a titre } \\
\text { of } 1 / 4 \text { etc and } 0 \text { for absence of antibodies) }\end{array}$ \\
PRIMPEAK Parasitological variable reflecting the primary peak in experiment 1: \\
mean log epg from D24 to D37** in group 1 \\
mean log epg from D56 to D67 in group 2 \\
mean log epg from D88 to D107 in group 3
\end{tabular}

Thus, in each of the 3 groups of experiment 1 , a peak faecal egg count was observed after the primary infection (fig 1). This peak was located from D24-D37 in group 1, from D56-D57 in group 2 and from D88-D107 in group 3: the PRIMPEAK variable reflects this peak.

In groups 1 and 2 of experiment 1 , the secondary infection was followed by a very large drop in faecal egg counts (from D39 to D46 in group 1 and from D74 to D81 in 


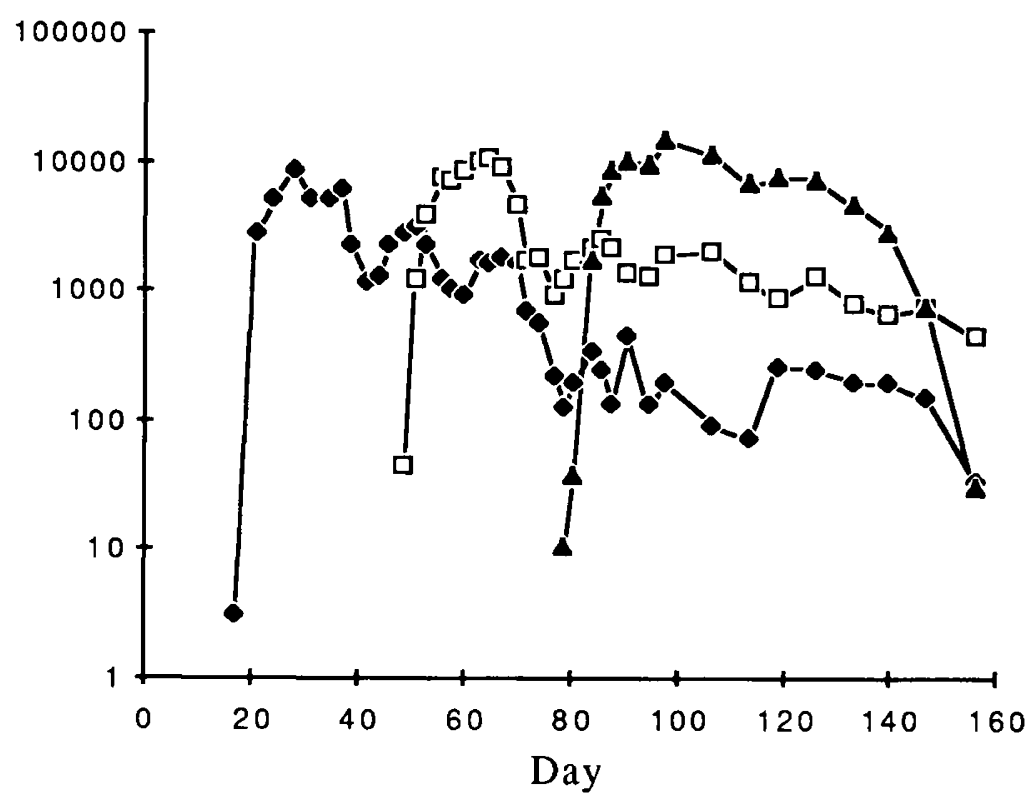

Fig 1. Mean kinetics of faecal egg output in the 3 groups of experiment 1. Group 1 (3 infections on d D0, D32 and D64 with 5000, 10000 and 20000 larvae, respectively); $-\square-$ Group 2 (2 infections on d D32 and D64 with 10000 and 20000 larvae, respectively); - Group 3 ( 1 infection on d D64 with 20000 larvae).

group 2): this was the classical self-cure phenomenon. Variable SELFCURE reflects this phenomenon; it is defined as the difference between the primary peak and the depression subsequently to the self-cure. A secondary peak could be observed immediately after this depression (D46 to D53 in group 1 and D84 to D88 in group 2): variable $S E C P E A K$ reflects this peak.

In experiments $2,3,4$ and 5 , the faecal egg counts increased after the infection (fig 2). Variables PEAKEXP2, PEAKEXP3, PEAKEXP 4 and PEAKEXP5 reflect the high egg counts after the infection (from D27-D48 in experiment 2, D26-D54 in experiment 3, D26-D55 in experiment 4 and D28-D52 in experiment 5). The synthetic variable PEAK235 is the mean of the 3 variables previously defined in expriment 2 and in its 2 replications, ie experiments 3 and 5 also involving 2 groups of animals (a group drenched before infection and a non-drenched group). The synthetic variable PEAK235 does not include experiment 4 in which all animals were drenched prior to infection.

The haematological parameters are defined as means of given measures over certain periods. The choice of periods here is again based on a kinetic examination. The number of red blood cells, the packed cell volume and haemoglobin content decreased during the period corresponding to the primary egg count peak: from D23-D39 in group 1, D53-D67 in group 2 and D88-D102 in group 3 (figs 3a, b, c). Variables RBCPRIM, PCVPRIM and HCPRIM, respectively account for this decrease in the 3 previously cited parameters. 

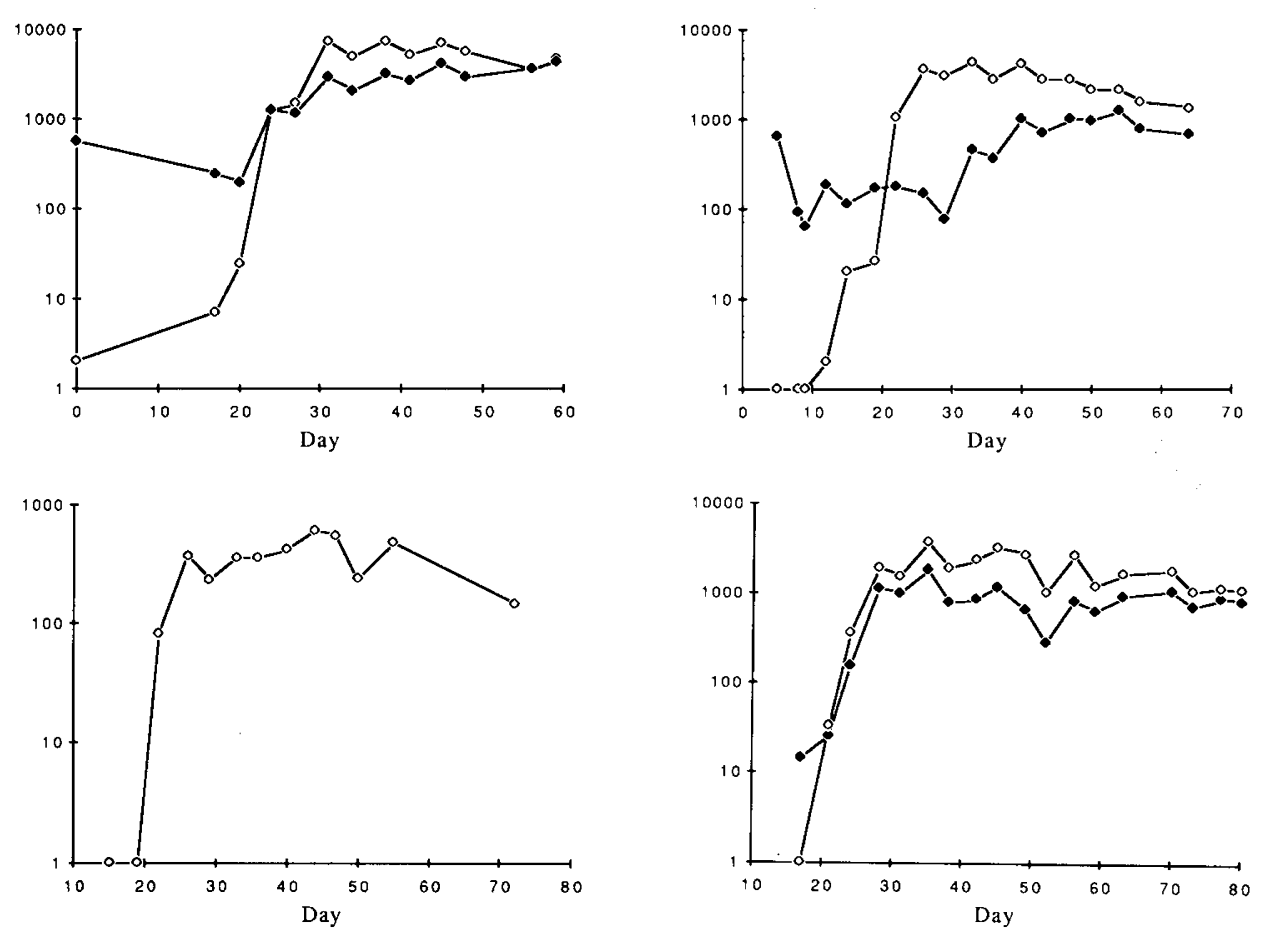

Fig 2. Mean kinetics of faecal egg output in experiments 2 (fig 2a), 3 (fig 2b), 4 (fig 2c) and 5 (fig 2d). $\checkmark$-Group drenched prior to infection on day DO (with 10000 larvae); Group non-drenched prior to infection on day D0 (with 10000 larvae).

\section{Factors}

The factors of variation considered are given in table II. Two of these factors (HBALLELE, the haemoglobin allele received from the sire and OLALLELE, the $O L A$ haplotype received from the sire) are nested within sire. According to analyses, the response to immunization with HSA was considered as a variable or a factor.

\section{Method of analysis}

\section{Analysis of the humoral immune response}

Two methods were used for the statistical analysis of the humoral immune response, ie $\chi^{2}$ test and analysis of variance.

Chi-square tests of independence were carried out between the RESPOND factor (accounting for the immunization "responder" or "non-responder" character) and various other factors of variation of table II (sire, haemoglobin genotype and $O L A$ haplotypes).

Analysis of variance were performed on variable ANTIHSA, accounting for the immune response to aggregated human serum albumin (table III). The number of experimental animals was not large enough to make an analysis simultaneously 

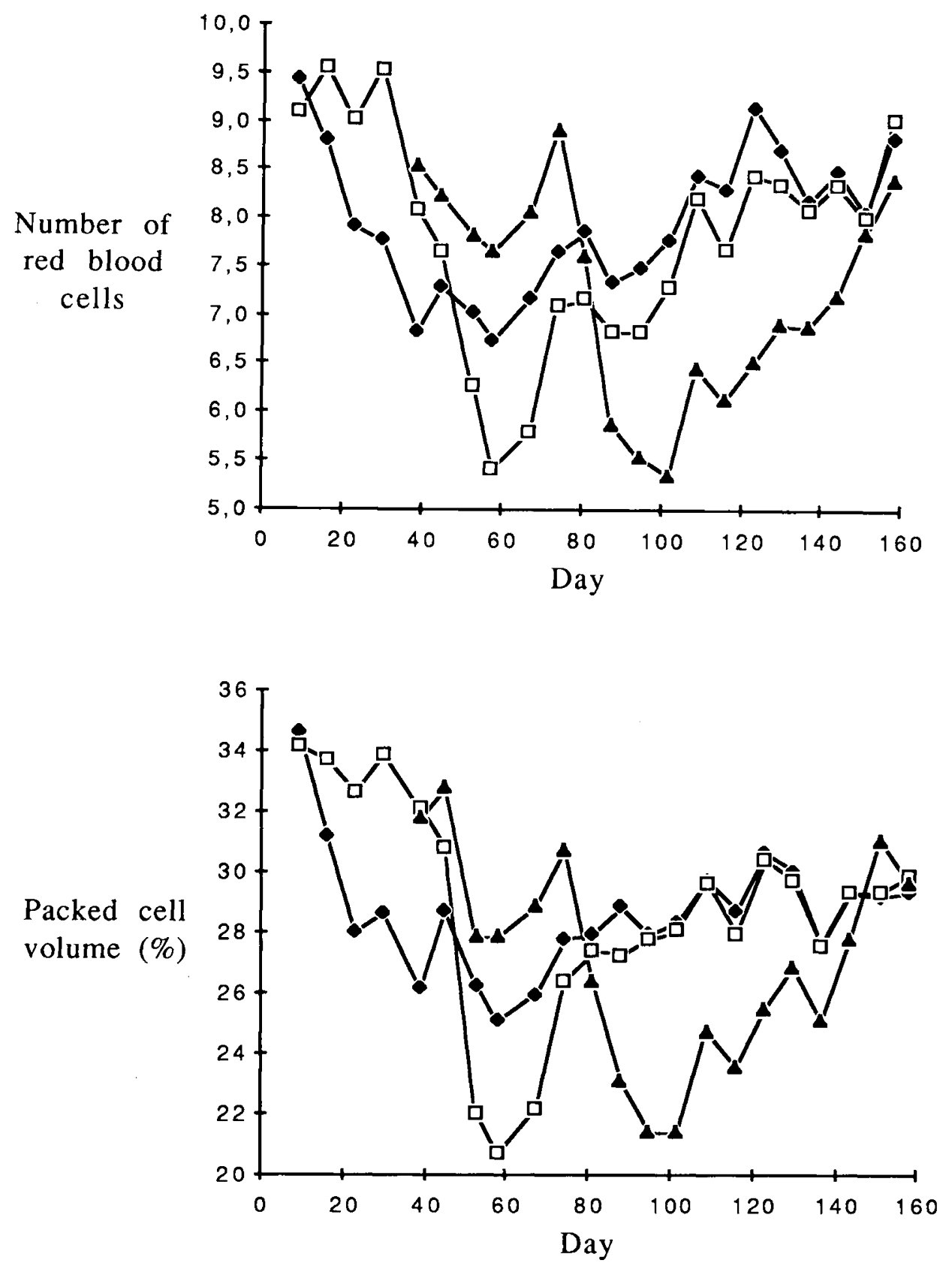

Fig 3 (continued) 


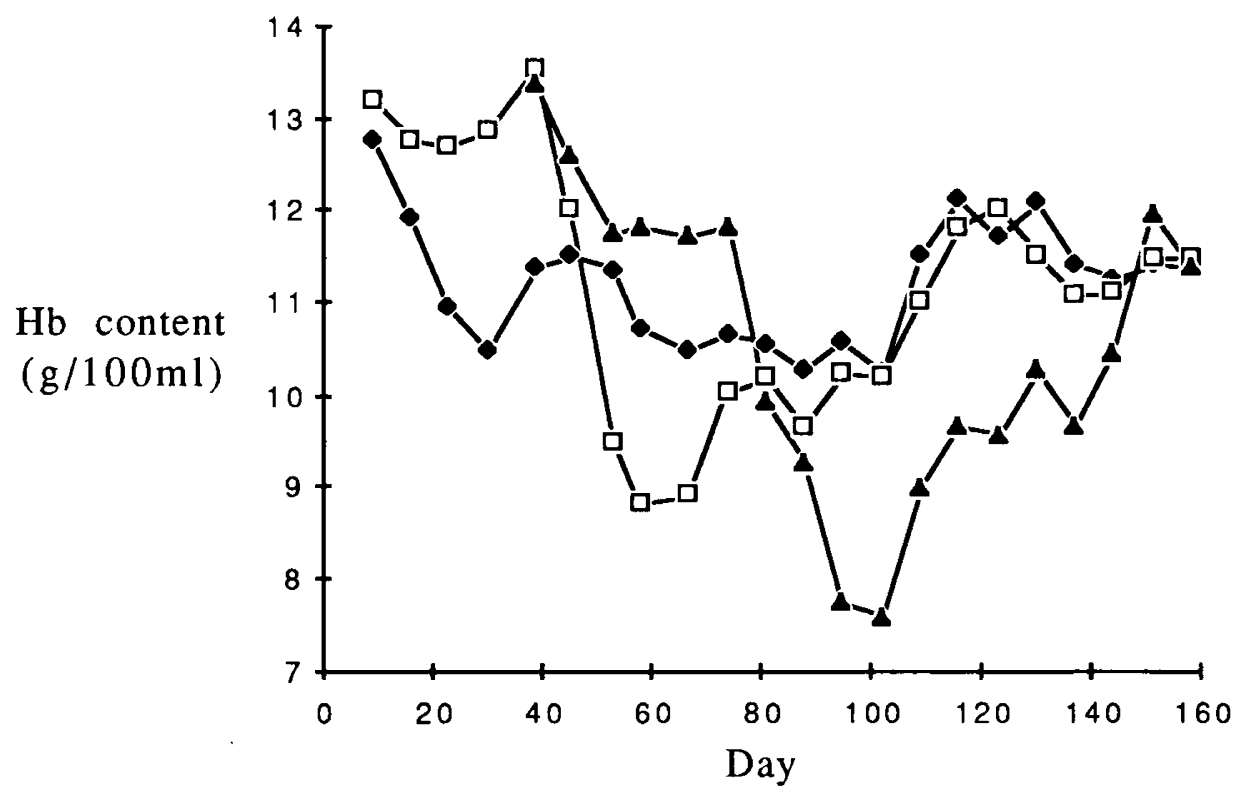

Fig 3. Mean kinetics of the 3 haematological parameters measured in the groups of experiment 1 , ie number of red blood cells per $\mathrm{mm}^{3}$ (fig $3 \mathrm{a}$ ), packed cell volume (fig 3b) and haemoglobin content (fig 3c).-Group 1 (3 infections on d D0, D32 and D64 with 5000,10000 and 20000 larvae, respectively); $\rightarrow-$ Group 2 (2 infections on D32 and D64 with 10000 and 20000 larvae, respectively). - - Group 3 (1 infection on D64 with 20000 larvae).

including all factors of variation; there would have been numerous either empty or low cells. Accordingly, several analysis of variance models were used each involving a small number of factors. This can also be applied to the analyses of variance of the parasitological and haematological variables, treated in the following paragraphs.

\section{Analysis of the parasitological and haematological variables of experiment 1}

Table IV shows the analysis of variance models applied to the parasitological and haematological variables of experiment 1 . When the factors did not include $R E$ $S P O N D$ (immunization "responder" or "non-responder" trait) or TITRE (category of anti-HSA antibody titre), the $A N T I H S A$ variable (reflecting the humoral response) was added in order to study its correlation with the parasitological and haematological variables. The same procedure was used for analysis of the variables of experiments 2, 3, 4 and 5 .

\section{Analysis of the parasitological variables of experiments 2, 3, 4 and 5}

Table $\mathrm{V}$ gives the models of the analyses of variance performed on the parasitological variables of experiments 2, 3, 4 and 5. Analyses of variables of experiments 2, 3 and 5 included necessarily factor GROUP235 corresponding to the group (a group drenched before infection, a non-drenched group). This was not the case for analyses 
Table II. List of factors of variation. $O L A-P 2^{*}$ haplotype is an alternative definition of $O L A-P 21$ ) haplotype (all animals possessing $O L A-P 21$ possess $O L A-P 21^{*}$ but the reverse is not the case). ${ }^{*} \mathrm{HSA}$ : aggregated human serum albumin.

\begin{tabular}{ll}
$\begin{array}{l}\text { Name of } \\
\text { factor }\end{array}$ & Definition of factor \\
\hline SIRE & Sire \\
HBGENO & Haemoglobin genotype \\
HBALLELE & Haemoglobin allele received from the sire (factor nested within sire) \\
OLA-P3 & ) \\
OLA-P3+13 & ) \\
OLA-P13 & OLA-P14 \\
OLA-P14+7 & Presence or absence of the 9 detected $O L A$ haplotypes \\
OLA-P14+9 & ) \\
OLA-P21 & \\
OLA-P21* & ) \\
OLA-P22 & \\
OLALLELE & OLA haplotype received from the sire (factor nested within sire) \\
TITRE & Category of anti-HSA antibody titre* (1/2 to $1 / 8,1 / 16$ to $1 / 64$, \\
& $1 / 128$ to 1/512 and 0) \\
RESPOND & HSA immunization "responder" or "non-responder" character \\
GROUP1 & Group in experiment 1 \\
\hline
\end{tabular}

Table III. Models of analysis of variance of the ANTIHSA reflecting the humoral immune response to injection of aggregated human serum albumin. ${ }^{*}$ Models are crossed and additive unless a statement is made to the contrary. Abbreviations of factors are given in table II.

\begin{tabular}{lcl}
\hline Model No & Analysed variable & Factors in the model $^{*}$ \\
\hline 1 & ANTIHSA & SIRE \\
2 & ANTIHSA & HBGENO \\
$3-11$ & ANTIHSA & OLA-P3 to OLA-P22 \\
12 & ANTIHSA & SIRE, HBGENO \\
13 & ANTIHSA & SIRE, HBALLELE (nested within SIRE) \\
$14-22$ & ANTIHSA & SIRE, OLA-P3 to OLA-P22 \\
23 & ANTIHSA & SIRE, OLALLELE (nested within SIRE) \\
\hline
\end{tabular}

of the variable of experiment 4 , since in this experiment all animals were given the anthelmintic treatment before infection.

Analysis of various parasitological variables considered as repeated measures of the same character

A new approach consists of considering that the parasitological variables $P R I M-$ $P E A K, P E A K E X P 2, P E A K E X P 3, P E A K E X P 4$ and $P E A K E X P 5$ (referring to 
Table IV. Models of analyses of variance of parasitological and haematological variables in experiment $1 .{ }^{*}$ Models are crossed and additive unless a statement is made to the contrary. ${ }^{* *}$ Between brackets: the $A N T I H S A$ variable included in the analysis for study of correlations with other variables. ${ }^{* * *}$ Factor nested within SIRE. Abbreviations of variables and factors are given in tables I and II, respectively.

\begin{tabular}{|c|c|c|}
\hline Model No & Analysed variables & Factors in the model ${ }^{*}$ \\
\hline 24 & $\begin{array}{l}\text { PRIMPEAK, SECPEAK, SELFCURE, } \\
\text { RBCPRIM, PCVPRIM, HCPRIM }\end{array}$ & GROUP1, RESPOND \\
\hline $\begin{array}{l}25 \\
26\end{array}$ & $\begin{array}{l}\text { The same } \\
\text { The same }\left(+A N T I H S A^{* *}\right)\end{array}$ & $\begin{array}{l}\text { GROUP1, TITRE } \\
\text { GROUP1 }\end{array}$ \\
\hline 27 & The same $\left(+A N T I H S A^{* *}\right)$ & GROUP1, SIRE \\
\hline 28 & The same (+ ANTIHSA $\left.{ }^{* *}\right)$ & GROUP1, HBGENO \\
\hline 29 & The same $\left(+A N T I H S A^{* *}\right)$ & GROUP1, SIRE, HBALLELE $E^{* * *}$ \\
\hline $30-38$ & The same $\left(+\right.$ ANTIHSA $\left.^{* *}\right)$ & GROUP1, OLA-P3 to OLA-P22 \\
\hline 39 & The same $\left(+A N T I H S A^{* *}\right)$ & GROUP1, SIRE, OLALLELE \\
\hline
\end{tabular}

Table V. Models of analyses of variances of parasitological variables in experiments 2, 3,4 and 5. ${ }^{*}$ Models are crossed and additive unless a statement is made to the contrary. ${ }^{* *}$ Between brackets: variables included in the analysis for study of correlations with other variables. ${ }^{* * *}$ Factor nested within SIRE. Abbreviations of variables and factors are given in tables I and II, respectively.

\begin{tabular}{|c|c|c|}
\hline Model No & Analysed variables & Factors in the model ${ }^{*}$ \\
\hline 40 & $\begin{array}{l}P E A K E X P 2, P E A K E X P 3, \\
P E A K E X P 5, \\
P E A K 235(+P E A K E X P 4)^{* *}\end{array}$ & GROUP235, RESPOND \\
\hline 41 & The same & GROUP235, TITRE \\
\hline 42 & The same $(+A N T I H S A)$ & GROUP235 \\
\hline 43 & The same $(+A N T I H S A)$ & GROUP235, SIRE \\
\hline 44 & The same $(+A N T I H S A)$ & GROUP235, HBGENO \\
\hline $\begin{array}{l}45 \\
46-54\end{array}$ & $\begin{array}{l}\text { The same }(+A N T I H S A) \\
\text { The same }(+A N T I H S A)\end{array}$ & $\begin{array}{l}\text { GROUP235, SIRE, HBALLELE*** } \\
\text { GROUP235, OLA-P3 to OLA-P22 }\end{array}$ \\
\hline & $\begin{array}{l}\text { The same }(+A N T I H S A) \\
P E A K E X P 4\end{array}$ & $\begin{array}{l}\text { GROUP235, SIRE, OLALLELE } \\
\text { RESPOND }\end{array}$ \\
\hline & $\begin{array}{l}\text { PEAKEXP4 } \\
P E A K E X P 4(+A N T I H S A)\end{array}$ & $\begin{array}{l}\text { TITRE } \\
\text { SIRE }\end{array}$ \\
\hline & $P E A K E X P 4(+A N T I H S A)$ & HBGENO \\
\hline & PEAKEXP4 $(+A N T I H S A)$ & SIRE, $H B A L L E L E^{* * *}$ \\
\hline $61-69$ & PEAKEXP4 (+ANTIHSA) & $O L A-P 3$ to $O L A-P 22$ \\
\hline 70 & $P E A K E X P 5(+A N T I H S A)$ & $S I R E, O L A L L E L E^{* * *}$ \\
\hline
\end{tabular}

experiments $1,2,3,4$ and 5, respectively) constitute repeated measures of the same parasitological overall variable $O V E R A L L$. Table VI gives models of analyses of variance on the $O V E R A L L$ variable. Each model includes necessarily: 
- the EXPGROUP factor corresponding to the experiment and group combination in which the OVERALL variable was measured;

- the ANIMAL factor corresponding to the experimental animal in which the measure was made.

Table VI. Models of analyses of variance of the overall parasitological OVERALL variable. * Models are crossed and additive unless a statement is made to the contrary. Abbreviations are given in text and table II.

\begin{tabular}{|c|c|c|}
\hline Model No & Analysed variable & Factors in the model ${ }^{*}$ \\
\hline $\begin{array}{l}71 \\
72\end{array}$ & $\begin{array}{l}\text { OVERALL } \\
\text { OVERALL }\end{array}$ & $\begin{array}{l}\text { EXPGROUP, ANIMAL } \\
\text { EXPGROUP, RESPOND, ANIMAL (nested within } \\
\text { RESPOND) }\end{array}$ \\
\hline 73 & OVERALL & $\begin{array}{l}\text { EXPGROUP, TITRE, ANIMAL (nested within } \\
\text { TITRE) }\end{array}$ \\
\hline 74 & OVERALL & $\begin{array}{l}\text { EXPGROUP, SIRE, ANIMAL (nested within } \\
\text { SIRE) }\end{array}$ \\
\hline 75 & OVERALL & $\begin{array}{l}\text { EXPGROUP, HBGENO, ANIMAL (nested within } \\
\text { HBGENO) }\end{array}$ \\
\hline $76-84$ & OVERALL & $\begin{array}{l}\text { EXPGROUP, OLA-P3 to OLA-P22, ANIMAL } \\
\text { (nested within } O L A-P 3 \text { to OLA-P22) }\end{array}$ \\
\hline
\end{tabular}

\section{RESULTS}

\section{Analysis of the humoral immune response}

Chi-square tests of independence between the "responder" character and various other factors (sire, haemoglobin genotype and $O L A$ haplotypes)

No $\chi^{2}$ was significant at the 0.05 level, with the exception of the test of independence between the "responder" character and the $O L A-P 14+9$ haplotype $\left(\chi_{1 d f}^{2}=5.953\right.$, significant at the 0.02 level) : this $\chi^{2}$ resulted from a preferential association between the "responder" character and the $O L A-P 14+9$ haplotype.

\section{Analyses of variance of the ANTIHSA variable reflecting the humoral immune response}

Among the 23 analyses of variance described in table III, only analyses no 8 and 19 showed a significant effect at the 0.05 level; in both cases, it was the effect of the $O L A-P 14+9$ haplotype whose presence in the studied sample was related to an increase in the level of anti-HSA antibodies. 
Analysis of the parasitological and haematological variables of experiment 1

Table VII summarizes the results of the analyses of variance whose models are described in table IV. Table VIII gives the residual correlations calculated on the parasitological and haematological variables relative on the primary peak of experiment 1 and on the immunological $A N T I H S A$ variable. Table IX gives the residual correlations calculated on all parasitological variables of experiment 1 (relative to the primary peak, secondary peak and to the self-cure) as well as on the immunological $A N T I H S A$ variable.

Table VII. Statistically significant effects evidenced by analyses of variance of the variables in experiment 1 . Lines : factors, Columns: variables. ${ }^{+},{ }^{*},{ }^{* *} ;{ }^{* * *}$ : significant effects at the $0.10,0.05,0.01$ and 0.001 levels, respectively. The numbers correspond to the model Nos of the analyses of variance resulting in significant effects; these Nos refer to table IV. In each factor $x$ variable cell, only the highest significant effects are indicated (among all those encountered). Abbreviations of variables and factors are given in tables I and II, respectively.

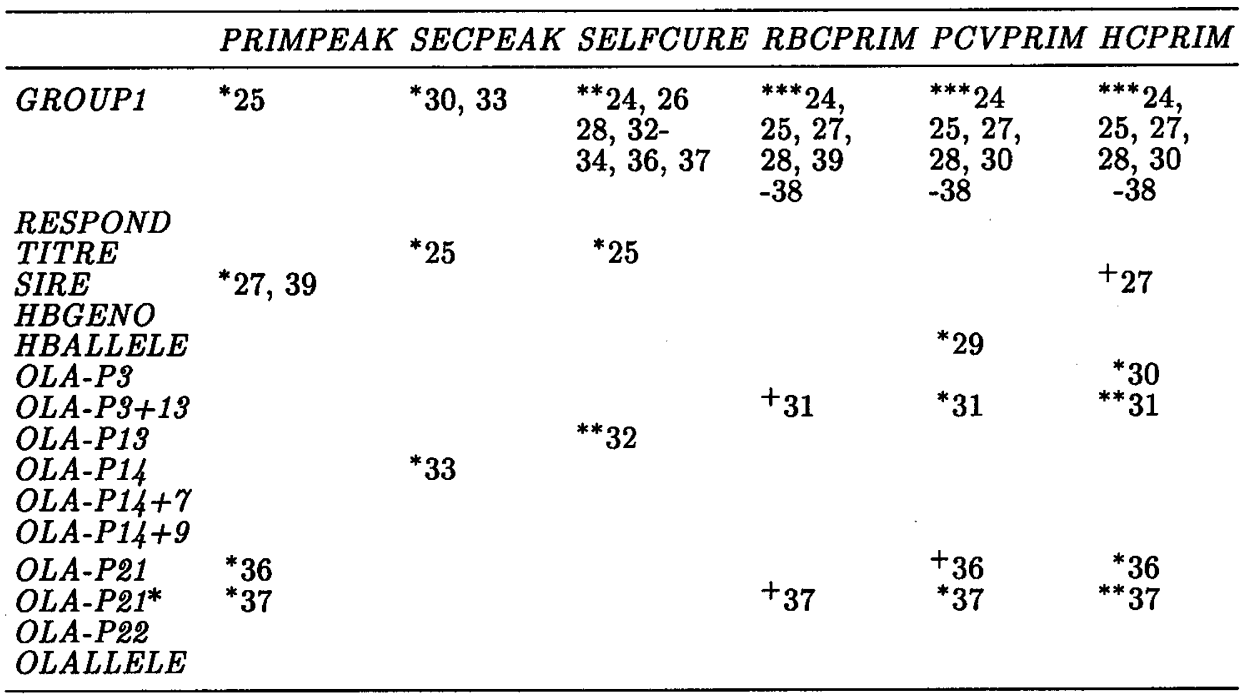

\section{Analysis of the parasitological variables of experiments 2, 3, 4 and 5}

Table $\mathrm{X}$ summarizes the results of the analyses of variance whose models are described in table V. Table XI gives the residual correlations calculated on the parasitological variables of experiments 2, 3, 4 and 5 as well as on the immunological ANTIHSA variable. 
Table VIII. Residual correlations calculated from the parasitological and haematological variables relative to the primary peak in experiment 1 as well as from the immunological $A N T I H S A$ variable using model No 26 with the group (GROUP1) as the sole factor of variation. ${ }^{+},{ }^{*},{ }^{* *},{ }^{* * *}$ : coefficient of correlation significantly different from zero at the levels $0.10,0.05,0.01$ and 0.001 , respectively. Abbreviations of variables are given in table I.

\begin{tabular}{lllll}
\hline PREMPEAK & RBCPRIM & PCVPRIM & HCPRIM & \\
\hline RBCPRIM & $-0.68^{* * *}$ & & & \\
PCVPRIM & $-0.62^{* * *}$ & $0.88^{* * *}$ & & \\
HCPRIM & $-0.61^{* * *}$ & $0.86^{* * *}$ & $0.89^{* * *}$ & \\
ANTIHSA & 0.01 & 0.16 & $0.24^{+}$ & 0.16 \\
\hline
\end{tabular}

Table IX. Residual correlations calculated from the parasitological variables relative to the primary peak, secondary peak and self-cure in experiment 1 as well as from the immunological $A N T I H S A$ variable using model No 26 with the group (GROUP1) as the sole factor of variation. ${ }^{* * *}$ : coefficient of correlation significantly different from zero at the level 0.001. Abbreviations of variables are given in table I.

\begin{tabular}{lccc}
\hline & PRIMPEAK & SECPEAK & SELFCURE \\
\hline SECPEAK & $0.55^{* * *}$ & & \\
SELFCURE & -0.22 & $-0.71^{* * *}$ & \\
ANTIHSA & 0.05 & 0.19 & -0.17 \\
\hline
\end{tabular}

\section{Analysis of the various parasitological variables considered as repeated measures of the same character}

Table XII summarizes the results of the analyses of variance whose models are described in table VI.

The repeatability of the character measured by the OVERALL variable was estimated in model No 71 (including the crossed EXPGROUP and ANIMAL factors) by the intra-class coefficient of correlation (ratio of "individual" variance to the sum of "individual" variance and residual variance): the estimated repeatability was 0.26 .

Figure 4 illustrates the effect of the TITRE factor (anti-HSA antibody titre) on the overall parasitological $O V E R A L L$ variable.

\section{DISCUSSION}

\section{Phenotypic relationships between the various parasitological variables}

A highly significant $(P<0.001)$ positive residual correlation was observed in experiment 1 between the variables reflecting the primary and secondary peak faecal egg counts. In contrast, these 2 variables were negatively correlated with 
Table X. Statistically significant effects evidenced by analyses of variance of the parasitological variables in experiments $2,3,4$ and 5 . Lines: factors, Columns: variables. ${ }^{+},{ }^{*},{ }^{* *}$, ${ }^{* * *}$ : significant effects at the $0.10,0.05,0.01$ and 0.001 levels, respectively. The numbers correspond to the model Nos of the analyses of variance resulting in significant effects; these Nos refer to table V. In each factor $x$ variable cell, only the highest significant effects are indicated (among all those encountered). Abbreviations of variables and factors are given in tables I and II, respectively.

\begin{tabular}{|c|c|c|c|c|c|}
\hline & PEAKEXP2 & PEAKEXPЗ & $P E A K E X P 5$ & PEAK235 & $P E A K E X P 4$ \\
\hline GROUP235 & $\begin{array}{l}* 42,46,47 \\
49-51,53\end{array}$ & $\begin{array}{l}* * * 42,44 \\
46-53\end{array}$ & & ${ }^{* *} 49$ & \\
\hline $\begin{array}{l}\text { RESPOND } \\
\text { TITRE } \\
\text { SIRE } \\
\text { HBGENO }\end{array}$ & $+_{40}$ & $\begin{array}{l}+40 \\
+41\end{array}$ & +40 & +40 & ${ }^{*} 56$ \\
\hline $\begin{array}{l}H B A L L E L E \\
O L A-P 9 \\
O L A-P 3+13 \\
O L A-P 13\end{array}$ & $\begin{array}{r}+_{45} \\
{ }^{*} 47\end{array}$ & & & & \\
\hline$O L A-P 14$ & ${ }^{* *} 49$ & $* * 49$ & & $* * 49$ & +64 \\
\hline$O L A-P 14+7$ & +50 & & ${ }^{*} 50$ & +50 & \\
\hline $\begin{array}{l}O L A-P 14+9 \\
O L A-P 21 \\
O L A-P 21^{*} \\
O L A-P 22 \\
O L A L L E L E\end{array}$ & & ${ }^{+} 51$ & & & +66 \\
\hline
\end{tabular}

Table XI. Residual correlations calculated from the parasitological variables of experiments 2, 3, 4 and 5 as well as from the immunological $A N T I H S A$ variable in analysis of variance No 42 with the group (GROUP235) as the sole factor of variation. ${ }^{+},{ }^{*},{ }^{* *},{ }^{* * *}$ : coefficient of correlation significantly different from zero at the levels $0.10,0.05,0.01$ and 0.001 , respectively. Abbreviations of variables are given in table I.

\begin{tabular}{llllll}
\hline & PEAKEXP2 & PEAKEXP3 & PEAKEXP5 & PEAK295 & PEAKEXP4 \\
\hline PEAKEXP3 & $0.49^{* * *}$ & & & & \\
PEAKEXP5 & $0.34^{*}$ & $0.35^{*}$ & & & \\
PEAK235 & $0.82^{* * *}$ & $0.70^{* * *}$ & $0.60^{* * *}$ & & \\
PEAKEXP4 & $0.46^{* * *}$ & $0.38^{* *}$ & 0.14 & $0.46^{* * *}$ & \\
ANTIHSA & $0.26^{+}$ & $0.36^{*}$ & 0.17 & $0.31^{*}$ & $0.26^{+}$ \\
\hline
\end{tabular}

the variable reflecting the self-cure, the correlation being only highly significant $(P<0.001)$ between the self-cure and the secondary peak: in other words, the animals with the lowest faecal egg counts were also those that best expelled their parasites.

Positive (generally significant) residual correlations were observed in the successive experiments $2,3,4$ and 5 (table XI) between the variables accounting for 


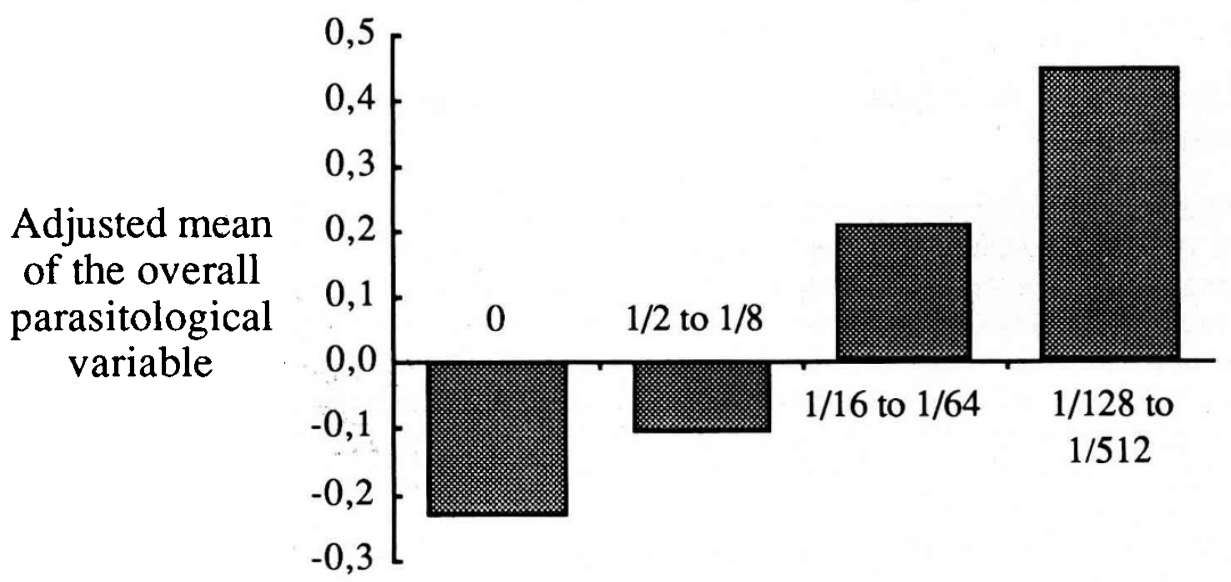

Fig 4. Adjusted means (expressed as a deviation from the general mean) of the overall parasitological OVERALL variable for the factor TITRE (anti-HSA antibody titre) in analysis of variance model No 73 including the factors EXPGROUP (experiment-group combination), TITRE and ANIMAL (experimental animal), nested in the previous one.

Table XII. Statistically significant effects evidenced by analyses of variance of the overall parasitological OVERALL variable. Lines: factors. Columns: variables. ${ }^{+},{ }^{*},{ }^{* *}$, ${ }^{* * *}$ : significant effects at the $0.10,0.05,0.01$ and 0.001 levels, respectively. The numbers correspond to the model Nos of the analyses of variance resulting in significant effects; these Nos refer to table VI. In each factor $x$ variable cell, only the highest significant effects are indicated (among all those encountered). Abbreviation factors are given in table II.

\begin{tabular}{lc}
\hline & OVERALL \\
\hline EXPGROUP & $* * * 71-84$ \\
ANIMAL & $* * 71-84$ \\
RESPOND & $* 72$ \\
TITRE & $* 73$ \\
SIRE & +74 \\
HBGENO & \\
OLA-P3 & \\
OLA-P3+13 & \\
OLA-P13 & \\
OLA-P14 & $* 79$ \\
OLA-P14+7 & +80 \\
OLA-P14+9 & +81 \\
OLA-P21 & \\
OLA-P21* & \\
OLA-P22 & \\
\hline
\end{tabular}


the egg counts. The highly significant effect of the ANIMAL factor on the overall parasitological OVERALL variable (table XII) illustrates the repeatability of the mean egg output during the peaks of the 5 successive infection experiments.

\section{Phenotypic relationships between faecal egg counts and degree of anaemia}

There were highly significant $(P<0.001)$ correlations between the mean number of red blood cells per $\mathrm{mm}^{3}$ of blood, the average packed cell volume and the mean level of haemoglobin during the primary peak of eggs passed in experiment 1 (table VIII). The PRIMPEAK variable, reflecting the peak faecal egg counts during primary infection was negatively correlated with the 3 haematological variables. This corresponds to the phenomenon of anaemia classically associated to large faecal egg counts (Whitlock, 1955, 1958; Evan et al, 1963; Pradhan and Johnstone, 1972; Altaif and Dargie, 1978a, b; Roberts and Swan, 1982; Albers et al, 1984).

\section{Effect of primary dose of infective larvae of faecal egg counts and anaemia}

The factor GROUP1 (group in experiment 1) had a significant effect on all parasitological and haematological variables measured during the primary peak of experiment 1 (table VII): as expected, the larger the larval intake, the higher the faecal egg counts and the degree of anaemia (figures 1 and 3).

\section{Effect of vaccination on immunity to the parasite}

Considering the kinetics of faecal egg output in group 1 of experiment 1 (figure 1): the peak faecal egg counts after the lst infection (with 5000 larvae) was higher than the peak after the 2nd infection (with 10000 larvae) which was higher than the peak after the 3rd infection (with 20000 larvae). Likewise, in group 2 of experiment 1 (figure 1), the primary peak exceeded the secondary peak although the 2nd dose of infective larvae was 2-fold higher than the lst one (20000 larvae instead of 10000).

With the same dose of infective larvae (10000 larvae on D32 or 20000 larvae on D64), animals which had previously experienced infection with $H$ contortus reacted by eliminating fewer eggs than those infected with the parasite for the first time.

These observations (based on figure 1 and confirmed statistically by analyses of variances not shown here) illustrate the phenomenon of immunity to the parasite (ie protection) acquired by "vaccination", $i e$ by previous infection with the parasite (Clunies Ross, 1932; Luffau, 1975; Luffau et al, 1981a, b).

\section{Effect of anthelmintic treatment on immunity to the parasite}

In experiments 2 and 3 , the group drenched before infection eliminated significantly more eggs than the non-drenched group (figure 2 and first line of table $\mathrm{X}$ ); the anthelmintic treatment substantially reduced the immunity acquired previously by contact with the parasite. The phenomenon was more marked in experiment 3 which was a replication of experiment 2 . In experiment 5 , the same trend was observed (figure 2), but the difference between the 2 groups was not significant (table $\mathrm{X}$ ). Thus, total elimination of residual worms by anthelmintic treatment prior to D0 
of the previous experiment (experiment 4) seemed to have reduced the difference between the 2 groups.

All these results, which show the reduction of immunity to the parasite after anthelmintic treatment, confirm those obtained by Benitez-Usher et al (1977) according to whom application of such a treatment after vaccination with irradiated larvae lowered the immunity to the parasite.

\section{Phenotypic relationships between resistance to parasitism and humoral immunity}

Factors relating to the anti-HSA antibody titre (RESPOND and TITRE) had significant effects on various parasitological variables of experiments 1 (table VII), $2,3,4$ and 5 (table $\mathrm{X}$ ) as well as the overall parasitological OVERALL variable (table XII). The higher the production of anti-HSA antibodies the larger the faecal egg counts, as shown by adjusted means in figure 4 . This positive relation between faecal egg count and humoral immunity is also illustrated by the positive coefficients of correlation between various parasitological variables reflecting the faecal egg output and the variable $A N T I H S A$ reflecting the humoral immunity (tables IX and $\mathrm{XI}$ ).

Contrary to the hypothesis put forward by Cuperlovic et al (1978), response to an immunization with aggregated human serum albumin is not a predictor of resistance to $H$ contortus. This negative correlation between resistance to helminths and response to an immunization has already been observed in mice (Blum and Cioli, 1978; Deelder et al, 1978; Perrudet-Badoux et al, 1978; Wakelin, 1978). In sheep, Albers et al (1984) did not find any significant correlation between resistance to $H$ contortus and response to an immunization with chicken red blood cells.

\section{Sire effect on resistance to $H$ contortus}

Significant sire effects were evidenced on the PRIMPEAK variable accounting for the primary peak faecal egg counts in experiment 1 (table VII) and on the overall parasitological $O V E R A L L$ variable pertaining to all experiments (table XII): these effects were significant at the 0.05 and 0.10 level, respectively. The number of experimental animals (51 offspring of 8 sires) was too small to make a heritability estimation. However, our results are in favour of a sire effect on resistance; they are in keeping with those of Le Jambre (1978), Albers et al (1984, 1987) and Piper (1987) who found a heritability ranging from $0.25-0.30$ for resistance to $H$ contortus.

\section{Relationships between haemoglobin system and immunological, para-} sitological and haematological variables

Neither the $H B G E N O$ factor (haemoglobin genotype) or the $H B A L L E L E$ factor (haemoglobin allele received from the sire) had any significant effect at the 0.05 level on the immunological or parasitological variables, although the experiment was designed to verify the existence of such effects.

These findings do not agree with those of other authors (Evans et al, 1963; Jilek and Bradley, 1969; Radhakrishnan et al, 1972; Allonby and Urquhart, 1976; Altaif 
and Dargie, 1976, 1978a, b; Preston and Allonby, 1979; Dally et al, 1980; Luffau et al, 1981a, b; Courtney et al, 1985), but they are in keeping with the results of Le Jambre (1978), Riffkin and Dobson (1979), Courtney et al (1984), Riffkin and Yong (1984) and Albers and Burgess reported by Piper (1987), who did not find any relationship between resistance to $H$ contortus and haemoglobin system.

Thus, although our data do not lead to detection of any relationship of humoral responsiveness (to human serum albumin) or of resistance to $H$ contortus with the haemoglobin system, there is evidence of a statistically significant effect $(P<0.05)$ of the $H B A L L E L E$ factor (haemoglobin allele received from the sire) on the mean packed cell volume (table VII). Hence a relationship between haemoglobin system and post-infection degree of anaemia cannot be excluded. According to the adjusted means, it seems that animals carrying the $H b A$ allele were less anaemic than the others. These results are in agreement with those of Evans and Whitlock (1964), Radhakrishnan et al (1972), Altaif and Dargie (1976, 1978a, b) and Albers and Burgess reported by Piper (1987). The post-infection differences observed between animals of various haemoglobin genotypes might simply be due to differences existing in non-infected animals (Agar et al, 1972). These differences might arise from oxygen affinity differences between haemoglobins $A$ and $B$. Haemoglobin $A$ has a higher oxygen affinity: at equal pressure, it releases less oxygen, which might cause the creation of compensatory mechanisms in haemoglobin $A$ carriers (Agar et al, 1972).

Relationships between the $O L A$ system with immunological, parasitological and haematological variables

The results obtained show statistically significant effects of various $O L A$ haplotypes on the humoral response as well as on the faecal egg counts and the degree of anaemia after parasite infections (tables VII, X and XII). Thus, we cannot exclude the existence, within or close to the $O L A$ system, of genes affecting these various phenomena. These results disagree with those of Cooper et al reported by Piper (1987), who did not find any association between $O L A$ system and resistance to $H$ contortus. But they do agree with those of Outteridge et al (1984, 1985, 1986, 1987 and 1988) who found an association between the $O L A$ system and the response to a vaccination against Trichostrongylus colubriformis. A relationship between the major histocompatibility complex and resistance to nematode parasites has also been demonstrated in the case of the guinea pig-Trichostrongylus colubriformis system (Geczy and Rothwell, 1981) and the mouse-Trichostrongylus spiralis system (Wassom et al, 1979).

\section{CONCLUSION}

In terms of parasitology, the results obtained lead to a more accurate determination of a certain number of phenomena such as repeatability of faecal egg counts between infections, negative relationship between faecal egg count peaks and self-cure intensity, positive relationship between faecal egg counts and degree of anaemia, acquisition of immunity by previous contact with the parasite and reduction of this immunity by anthelmintic treatment. 
In terms of genetics, the results invalidate the hypothesis that homozygous sheep carriers of haemoglobin $A$ have lower faecal egg counts than the others as well as the hypothesis that animals with the best humoral immune response are the most resistant to parasitism. On the other hand, they do not exclude the hypothesis that genes within or close to the $O L A$ system might affect the resistance to $H$ contortus. The latter conclusion, in keeping with those of other studies, emphasizes the role of the $O L A$ system as a potential marker of resistance to parasitism.

\section{ACKNOWLEDGMENTS}

The authors are grateful to K Rérat (Unité Centrale de Documentation, INRA, Centre de Recherches de Jouy-en-Josas) for the translation of the manuscript.

\section{REFERENCES}

Agar NS, Evans JV, Roberts J (1972) Red blood cell potassium and haemoglobin polymorphism in sheep. A review. Anim Breed (Abstr) 40, 407-436

Albers GAA, Gray GD (1987) Breeding for worm resistance: a perspective. Int $J$ Parasitol 17, 559-566

Albers GAA, Burgess SE, Adams DB, Barker JSF, Le Jambre LF, Piper LR (1984) Breeding Haemonchus contortus resistant sheep - problems and prospects. In: Immunogenetic approaches to the control of endoparasites with particular reference to parasites of sheep, Proc of a workshop held at Sydney University, October 22-23 1983, on behalf of the Australian Wool Corporation, CSIRO, East Melbourne, 41-52

Albers GAA, Gray GD, Piper LR, Barker JSF, Le Jambre LF, Barger IA (1987) The genetics of resistance and resilience to Haemonchus contortus infection in young Merino sheep. Int J Parasitol 17, 1355-1363

Allonby EW, Urquhart GM (1976) A possible relationship between haemonchosis and haemoglobin polymorphism in Merino sheep in Kenya. Res Vet Sci 20, 212214

Altaif KI, Dargie JD (1976) Genetic resistance of sheep to Haemonchus contortus. In: Nuclear techniques in animal production and health, Proc of a Symp, Vienna, 2-6 February 1976, jointly organized by the IAEA and FAO, International Atomic Energy Agency, Vienna, 449-461

Altaif KI, Dargie JD (1978a) Genetic resistance to helminths. The influence of breed and haemoglobin type on the response of sheep to primary infections with Haemonchus contortus. Parasitology 77, 161-175

Altaif KI, Dargie JD (1978b) Genetic resistance to helminths. The influence of breed and haemoglobin type on the response of sheep to re-infection with Haemonchus contortus. Parasitology 77, 177-187

Benitez-Usher C, Armour J, Duncan JL, Urquhart GM, Gettingby G (1977) A study of some factors influencing the immunization of sheep against Haemonchus contortus using attenuated larvae. Vet Parasitol 3, 327-342 
Blum K, Cioli D (1978) Paradoxical behaviour of Biozzi high and low responder mice upon infection with Schistosoma mansoni. Eur J Immunol 8, 52-56

Cabaret J, Gruner L (1988) Genetic variability of resistance to parasites. In: Proceedings of the 3rd World Congress on Sheep and Beef Cattle Breeding, 19-23 June 1988, Paris, INRA Publications, Paris 1, 577-592

Clunies Ross I (1932) Observations on the resistance of sheep to infestation by stomach worm (Haemonchus contortus). J Council Scientific Industrial Research $5,73-80$

Colglazier MG, Lindahl IL, Turner JH, Wilson GI, Whitmore GE, Wilson RL (1968) Effect of management systems on the growth of lambs and development of internal parasitism. J Parasitol 54, 89-97

Courtney CH (1986) Host genetic factors in helminth control in sheep. Vet Clin North Am Food Anim Prac 2, 433-438

Courtney CH, Parker CF, McClure KE, Herd RP (1984) A comparison of the periparturient rise in fecal egg counts of exotic and domestic ewes. Int $J$ Parasitol 14, 377-381

Courtney CH, Parker CF, McClure KE, Herd RP (1985) Resistance of exotic and domestic lambs to experimental infection with Haemonchus contortus. Int $J$ Parasitol 15, 101-109

Cullen PR, Millot P, Nguyen TC (1985) Sheep histocompatibility antigens: a population level comparison test between lymphocyte antigens previously defined in France, England and Scotland, and sheep red cell groups. Anim Blood Groups Biochem Genet 16, 19-34

Cuperlovic K, Altaif KI, Dargie JD (1978) Genetic resistance to helminths: a possible relationship between haemoglobin type and the immune responses of sheep to non-parasitic antigens. Res Vet Sci 25, 125-126

Dally MR, Hohenboken W, Thomas DL, Craig AM (1980) Relationships between hemoglobin type and reproduction, lamb wool and milk production and healthrelated traits in crossbred ewes. J Anim Sci 50, 418-427

Deelder AM, Class FHJ, De Vries RRP (1978) Influence of the mouse H2 gene complex on experimental infection with Schistosoma mansoni. Trans $R$ Soc Trop Med Hyg 72, 321-322

Duncan JL, Smith WD, Dargie JD (1978) Possible relationship of levels of mucosal $\operatorname{IgA}$ and serum IgG to immune unresponsiveness of lambs to Haemonchus contortus. Vet Parasitol 4, 21-27

Evans JV, Whitlock JH (1964) Genetic relationship between maximum hematocrit values and hemoglobin type in sheep. Science 145, 1318

Evans JV, Blunt MH, Southcott WH (1963) The effects of infection with Haemonchus contortus on the sodium and potassium concentrations in the erythrocytes and plasma, in sheep of different haemoglobin types. Aust J Agric Res 14, 549-558

Geczy AF, Rothwell TLW (1981) Genes within the major histocompatibility complex of the guinea pig influence susceptibility to Trichostrongylus colubriformis infection. Parasitology 82, 281-286 
Holmes PH (1986) Pathophysiology of nematode infections. In: 6th Int Cong of Parasitology, Brisbane, 24-29 August 1986, Pergamon Press, Oxford, 443-451

Jarrett WFH, Jennings FW, McIntyre WIM, Mulligan W, Sharp NCC (1961) Studies on immunity to Haemonchus contortus infection: double vaccination of sheep with irradiated larvae. Am J Vet Res 22, 186-188

Jilek AF, Bradley RE (1969) Hemoglobin types and resistance to Haemonchus contortus in sheep. Am J Vet Res $30,1773-1778$

Knight RA, Rodgers D (1974) Age resistance of lambs to single inoculation with Haemonchus contortus. Proc of the Helminthological Society of Washington 41, 116

Le Jambre LF (1978) Host genetic factors in helminth control. In: The Epidemiology and Control of Gastrointestinal Parasites of Sheep in Australia (Donald AD, Southcott WH, Dineen JK, eds) CSIRO, Australia, 137-141

Luffau G (1975) Quelques problèmes posés par Haemonchus contortus ("ver de la caillette") en pathologie ovine. In: Premières Journées de la Recherche Ovine et Caprine INRA-ITOVIC, Les races prolifiques, tome 2 (espèce ovine), SPEOC, Paris, $472-480$

Luffau G, Péry P, Charley J (1981a) Réponse immunitaire chez les ovins infestés expérimentalement par Haemonchus contortus. Etude comparative chez le mâle et chez la femelle. Ann Rech Vét 12, 173-181

Luffau G, Péry P, Petit A (1981b) Self-cure and immunity following infection and reinfection in ovine haemonchosis. Vet Parasitol 9, 57-67

Manton VJA, Peacock R, Poynter D, Silverman P, Terry RJ (1962) The influence of age on naturally acquired resistance to Haemonchus contortus in lambs. Res Vet Sci 3, 308-314

Nguyen TC (1984) The immune response in sheep: analysis of age, sex and genetic effects on the quantitative antibody response to chicken red blood cells. Vet Immunol Immunopathol 5, 237-245

Nguyen TC, Bunch TD (1980) Blood groups and evolutionary relationships among domestic sheep (Ovis aries), domestic goat (Capra hircus), Aoudad (Ammotragus lervia) and European mouflon (Ovis musimon) Ann Genet Sel Anim 12, 169-180

Outteridge PM, Windon RG, Dineen JK, Dawkins HJS (1984) Association between lymphocyte antigens in sheep and responsiveness to vaccination against intestinal parasites. In: Immunogenetic approaches to the control of endoparasites with particular reference to parasites of sheep, Proceedings of a workshop held at Sydney University, October 22-23 1983, on behalf of the Australian Wool Corporation, 103-111, CSIRO, East Melbourne, 103-111

Outteridge PM, Windon RG, Dineen JK (1985) An association between a lymphocyte antigen in sheep and the response to vaccination against the parasite. Trichostrongylus colubriformis. Int J Parasitol 15, 121-127

Outteridge PM, Windon RG, Dineen JK, Smith EF (1986) The relationship between ovine lymphocyte antigens and faecal egg count of sheep selected for responsiveness to vaccination against Trichostrongylus colubriformis. Int $J$ Parasitol 16, 369-374 
Outteridge PM, Windon RG, Dinee JK, Stewart DJ, Skerman TM (1987) Breeding for parasite and footrot resistance in sheep using ovine lymphocyte antigen (OLA) markers. In: Merino improvement programs in Australia. Proceedings of a National Symposium, Leura, Australian Wool Corporation, Melbourne, 277-379

Outteridge PM, Windon RG, Dineen JK (1988) An ovine lymphocyte antigen marker for acquired resistance to Trichostrongylus colubriformis. Int J Parasitol $18,853-858$

Perrudet-Badoux A, Binaghi RA, Boussac-Aron Y (1978) Trichinella spiralis infection in mice: mechanism of the resistance in animals genetically selected for high and low antibody production. Immunology 35, 519-522

Piper LR (1987) Genetic variation in resistance to internal parasites. In: Merino improvement programs in Australia, Proceedings of a National Symposium, Leura, Australian Wool Corporation, Melbourne, 351-363

Pradhan SL, Johnstone IL (1972) Haemonchus contortus: haematological changes in lambs during prolonged exposure to daily and weekly doses of infective larvae. Parasitology 64, 153-160.

Preston JM, Allonby EW (1979) The influence of haemoglobin phenotype on the susceptibility of sheep to Haemonchus contortus infection in Kenya. Res Vet Sci $26,140-144$

Radhakrishnan GV, Bradley RE, Loggins RE (1972) Host responses of worm-free Florida native and Rambouillet lambs experimentally infected with Haemonchus contortus. Am J Vet Res 33, 817-823

Riffkin GG, Dobson C (1979) Predicting resistance of sheep to Haemonchus contortus infections. Vet Parasitol 5, 365-378

Riffkin GG, Yong WK (1984) Recognition of sheep which have innate resistance to trichostrongylid nematode parasites. In: Immunogenetic approaches to the control endoparasites with particular reference to parasites of sheep, Proceedings of a workshop held at Sydney University, October 22-23 1983, on behalf of the Australian Wool Corporation, CSIRO, East Melbourne, 30-38

Roberts JL, Swan RA (1981) Quantitative studies of ovine haemonchosis. 1. Relationship between faecal egg counts and total worm counts. Vet Parasitol $8,165-171$

Roberts JL, Swan RA (1982) Quantitative studies of ovine haemonchosis. 2. Relationship between total worm counts on Haemonchus contortus, haemoglobin values and bodyweight. Vet Parasitol 9, 201-209

Smith WD, Angus KW (1980) Haemonchus contortus: attempts to immunise lambs with irradiated larvae. Res Vet Sci 29, 45-50

Urquhart GM, Jarrett WFH, Jennings FW, McIntyre WIM, Mulligan W, Sharp NCC (1966a) Immunity to Haemonchus contortus infection: failure of Xirradiated larvae to immunize young lambs. Am J Vet Res 27, 1641-1643

Urquhart GM, Jarrett WFH, Jennings FW, McIntyre WIM, Mulligan W (1966b) Immunity to Haemonchus contortus infection: relationship between age and successful vaccination with irradiated larvae. Am J Vet Res 27, 1645-1648 
Wakelin D (1978) Genetic control of susceptibility and resistance to parasitic infection. Adv Parasitol 16, 219-308

Warwick BL, Berry RO, Turk RD, Morgan CO (1949) Selection of sheep and goats for resistance to stomach worms, Haemonchus contortus. J Anim Sci 8, 609-610

Wassom DL, David CS, Gleich GJ (1979) Genes within the Major Histocompatibility Complex influence susceptibility to Trichinella spiralis in the mouse. Immunogenetics 9, 491-496

Watson TG (1986) Immunity to gastrointestinal nematode parasites in domestic stock with particular reference to sheep: a review. Proc $N Z$ Soc Anim Prod 46, 15-22

Weir DM (1978) Passive haemagglutination with special reference to the tanned cell technique. In: Immunochemistry, Handbook of Experimental Immunology, Blackwell Sci Pub, 3rd edn, 1, 20

Whitlock JH (1955) A study of the inheritance to trichostrongylidosis in sheep. Cornell Vet 45, 422-439

Whitlock JH (1958) The inheritance of resistance to trichostrogylidosis in sheep. 1. Demonstration of the validity of the phenomena. Cornell Vet 48, 127-133

Whitlock JH, Madsen H (1958) The inheritance of resistance to trichostrogylidosis in sheep. 2. Observations on the genetic mechanism in trichostrogylidosis. Cornell Vet 48, 134-164

Wilson GI, Samson KS (1974) Immunity to Haemonchus sp in lambs: the immunizing effects of various methods of larval administration. Res Vet Sci 17, 390-394

Yazwinski TA, Goode L, Moncol DJ, Morgan GW, Linnerud AC (1980) Haemonchus contortus resistance in straightbred and crossbred Barbados Blackbelly sheep. $J$ Anim Sci 51, 279-284 